\title{
HAKIKAT PENDIDIKAN KARAKTER DENGAN SAINS (SALING BERIRISAN KAH?
}

\author{
Oni Sahroni ${ }^{1}$ \\ ${ }^{1}$ Fakultas Kesehatan, Universitas Muhammadiyah Tasikmalaya, J1. Tamansari No.KM 2,5, Mulyasari, \\ Kec. Tamansari, Tasikmalaya, Jawa Barat 46196 \\ e-mail: *1onssahroni@gmail.com
}

\begin{abstract}
ABSTRAK
Dua tujuan utama dalam pendidikan adalah membuat manusia yang cerdas secara kemampuan dan cerdas secara perilaku (karakter). Sains memberikan pemahman dan mengenai manusia dengan pencipta-Nya. Metode dalam penulisan artikel ini adalah kajian dari artikel yang berkaitan dengan pendidikan karakter dan sains. Melalui kajian ini dapat disimpulkan bahwa sains dan karakter memiliki irisan yang keduanya saling berhubungan. Sains memberikan pemahaman tentang manusia dan mengenali penciptanya, aktivitas sains memberikan sifat yang objektif dan jujur dalam menyampaikan hasilnya, dua sikap ini merupakan hal yang penting dalam memberikan pondasi karakter bagi seseorang.
\end{abstract}

Kata Kunci : Pendidikan Karakter, Sains

\section{PENDAHULUAN}

Sepanjang sejarahnya, di seluruh dunia ini, pendidikan pada hakikatnya memiliki dua tujuan, yaitu membantu manusia untuk menjadi cerdas dan pintar (smart), dan membantu mereka menjadi manusia yang baik (good) (Sudrajat, 2011). Menjadikan. Pendidikan merupakan upaya sadar dan terarah dari sekolomok orang untuk merubah pengetahuan dan perilaku kelompok tersebut (Aqil, 2017). Pembelajaran saing merupakan pembelajaran yang dapat memfasilitasi anak dalam memiliki karakter yang baik karena pada dasarnya saing memberikan pemahaman tentang penciptaan manusia dan unsur-unsurnya (Verawati \& Prayogi, 2016)(Muna et al., 2017)

Secara texbook kata sains ini bersal dari bahasa Latin, yakni scientia yang artinya secara sederhana adalah pengetahuan (knowledge). Begitu juga dalam bahasa Jerman, yaitu wissenchaft yang artinya keteraturan, pengetahuan yang terorganisir secara baik dan berformat. Sains diartikan sebagai pengetahuan yang secara sistematis tersusun (formatid) dan bersama-sama dalam suatu urutan tertentu (Ibrahim et al., 2019) (Prasetyo, 2013). Oleh karena itu orang sains dikenal dengan orang yang memiliki pemikiran yang sistematis dan terukur. Ini menjadi sifat dasar dari orang sains tersebut.

Aktivitas manusia yang berkenaan dengan Sains dicirikan oleh adanya proses berpikir yang terjadi di dalam pikiran siapapun yang terlibat di dalamnya. Kegiatan para peneliti/ ilmuwan yang berkaitan dengan akal, menggambarkan keingintahuan manusia dan keinginan mereka untuk memahami gejala alam dan akibatnya. Para pakar ilmu dan ilmuwan memiliki sikap, keyakinan, dan nilai- nilai yang memotivasi mereka untuk memecahkan persoalan- persoalan yang mereka temui di alam. Kegiatan pakar 
digerakkan oleh rasa keingintahuan yang sangat tinggi, nalar/imajinasi, dan pemikiran dalam riset mereka untuk memahami dan menjelaskan fenomenafenomena alam yang selalu berhubungan dengan kehidup manusia (Ibrahim et al., 2019).

Perkembangan sains tidak lepas dari keterlibatan imajinasi dan kreativitas manusia. Konsep ilmiah dalam sains tidak secara otomatis semata-mata dihasilkan dari data atau sejumlah analisis saja (Muna et al., 2017) (Sugiharto, 2011)(Shaumi, 2015). "Scientific attitudes (sikap ilmiah atau konsep), yaitu misalnya keyakinan nilai, gagasan, objektif, jujur, menghargai pendapat orang lian, dan sebagainya. Scientific processes or methods (metode ilmiah), yaitu suatu cara khusus dalam memecahkan problem misalnya seperti mengamati fakta, membuat hipotesis, merancang dan melaksanakan eksperimen, mengumpulkan, dan menyusun data, mengevaluasi data, menafsirkan, dan menyimpulkan data, serta membuat teori dan mengkomunikasikannya. Scientific products atau produk ilmiah yang berarti terdapat fakta, konsep, prinsip, hukum, teori tentang fenomena alam dan juga sebagainya. Sedangkan makna secara etimologi, Sains berasal dari bahasa latin yaitu Scientia yang berarti "pengetahuan" atau "mengetahui". (Nagy, R., Porder, S., Brando, P., Davidson, E., Figueira, A., Neill, Trumbore, S. 2017 ((Ibrahim et al., 2019)).

Berdasarkan pendapat tersebut menarik jika sain ini kita hubungkan dengan pendidikan karakter. Pendidikan karakter bukanlah berupa materi yang hanya bisa dicatat dan dihafalkan serta tidak dapat dievaluasi dalam jangka waktu yang pendek, tetapi pendidikan karakter merupakan sebuah pemblajaran yang teraplikasi dalam semua kegiatan siswa baik disekolah, lingkungan masyarakat dan dilingkungan dirumah melalui proses pembiasaan, keteladanan, dan dilakukan secara berkesinambungan (Choli, 2019)(Kosim, 2011). Berdasarkan pendapat tersebut jelaslah bahwa hasil dari pendidikan karakter tidak bisa di lihat dalam jangka yang pendek tetapi memerlukan jangka waktu yang panjang dan harus dilaksanakan secara berkesinambungan. Oleh karena itu pendidikan karakter perlu pembiasaan agar menjadi suatu karakter yang tertanam dalam dirinya.

Sementara untuk pengertian pendidikan karakater Lickona (1992) menyebutkan "character education is the deliberate effort to help people understand, care about, and act upon core ethical values (Ani, 2014) (Kunci, 2013)(Hasibuan et al., 2018)", hal ini berarti bahwa pendidikan karakter adalah upaya yang disengaja untuk membantu orang memahami, peduli, dan bertindak berdasarkan nilai-nilai etika inti.

Pendidikan karakter dalam konteks pendidikan di Indonesia adalah pendidikan nilai, yakni pendidikan nilai-nilai luhur yang bersumber dari budaya bangsa Indonesia sendiri, dalam rangka membina kepribadian generasi muda. Berdasarkan grand design yang dikembangkan Kemendiknas, secara psikologis dan sosial kultural pembentukan karakter dalam diri individu merupakan fungsi dari seluruh potensi individu manusia (kognitif, afektif, konatif, dan psikomotorik) dalam konteks interaksi sosial kultural (dalam keluarga, sekolah, dan masyarakat) dan berlangsung sepanjang hayat. Konfigurasi (Arif, 2017) (Susanti, 2013). Nilai lihur adalah nilai baik yang berkembang dalam budaya Indonesia dan menjadi ciri khas budaya tersebut, ini menjadikan kunci bahwa nilai luhur ini harus dipelihara agar menjadi warisan yang baik dari generasi ke generasi. Melalui tulisan ini akan di berikan pemahaman yang komprehensif bagaimana pembelajaran sains dan pendidikan karakter ada kaitannya sehingga kita bisa melihat dari dua sisi yang menarik dari keduanya.

\section{METODE}

Artikel ini dibuat dengan melakukan review terhadap artikel yang berkaitan dengan pendidikan karakter dan pembelajaran sains. Kemudian dari kedua tema tersebut ditarik irisan mengenai 
hubungannya sehingga pembahasan artikel ini lebih diarahkan kepada irisan dari keduanya.

\section{HASIL DAN PEMBAHASAN}

\section{Karakter dan Pendidikan Karakter}

UU No.20 tahun 2003 tentang Sistem Pendidikan Nasional, bahwa pendidikan nasional berfungsi mengembangkan kemampuan dan membentuk watak serta peradaban bangsa yang bermartabat dalam rangka mencerdaskan kehidupan bangsa, bertujuan untuk mengembangkan potensi peserta didik agar menjadi peserta didik yang beriman dan bertakwa kepada Tuhan Yang Maha Esa, berakhlak mulia, sehat, berilmu, cakap, kreatif dan menjadi warga negara yang demokrasi serta bertanggung jawab. Pendidikan nasional mempunyai misi mulia (mission sacre) yakni membangun pribadi yang yang memiliki ilmu pengetahuan, meningkatkan kemampuan teknis, mengembangkan kepribadian yang kokoh, membentuk karakter yang kuat (Zubaidah, 2011). Inilah yang menjadikan bahwa karakter menjadi sesuatu yang penting dalam membangung Sumber Daya Manusia yang unggul dan berdaya saing. Karakter menjadi sikap yang menjadikan dirinya memiliki kebiasaan yang baik.

Menurut Lickona (Sudrajat, 2011) ada tujuh alasan mengapa pendidikan karakter itu harus disampaikan. Ketujuh alasan yang dimaksud adalah sebagai berikut.

a. Cara terbaik untuk menjamin anakanak (siswa) memiliki kepribadian yang baik dalam kehidupannya.

b. Cara untuk meningkatkan prestasi akademik.

c. Sebagian siswa tidak dapat membentuk karakter yang kuat bagi dirinya di tempat lain

d. Persiapan siswa untuk menghormati pihak atau orang lain dan dapat hidup dalam masyarakat yang beragam.

e. Berangkat dari akar masalah yang berkaitan dengan problem moralsosial, seperti ketidaksopanan, ketidakjujuran, kekerasan, pelanggaran kegiatan

f. seksual, dan etos kerja (belajar) yang rendah.

g. Persiapan terbaik untuk menyongsong perilaku di tempat kerja.

h. Pembelajaran ni lai-ni lai budaya yang merupakan bagian dari kerja peradaban.

Kemdiknas (2011) mencanangkan strategi pembangunan karakter bangsa dengan langkah berikut. (1) Sosialisasi: penyadaran semua pemangku kepentingan akan pentingnya karakter bangsa. Media cetak dan elektronik perlu berperanserta dalam sosialisasi. (2) Pendidikan: formal (satuan pendidikan), nonformal (kegiatan keagamaan,kursus, pramuka dan lain lain), informal (keluarga, masyarakat, dan tempat kerja), forum pertemuan (kepemudaan). (3) Pemberdayaan: memberdayakan semua pemangku kepentingan (orang tua, satuan pendidikan, ormas, dan sebagainya) agar dapat berperan aktif dalam pendidikan karakter. (4) Pembudayaan: perilaku berkarakter dibina dan dikuatkan dengan penanaman nilai-nilai kehidupan agar menjadi budaya. (5) Kerjasama: membangun kerjasama sinergis antara semua pemangku kepentingan. Gambaran pendidikan sains di sekolah sebagai berikut: 


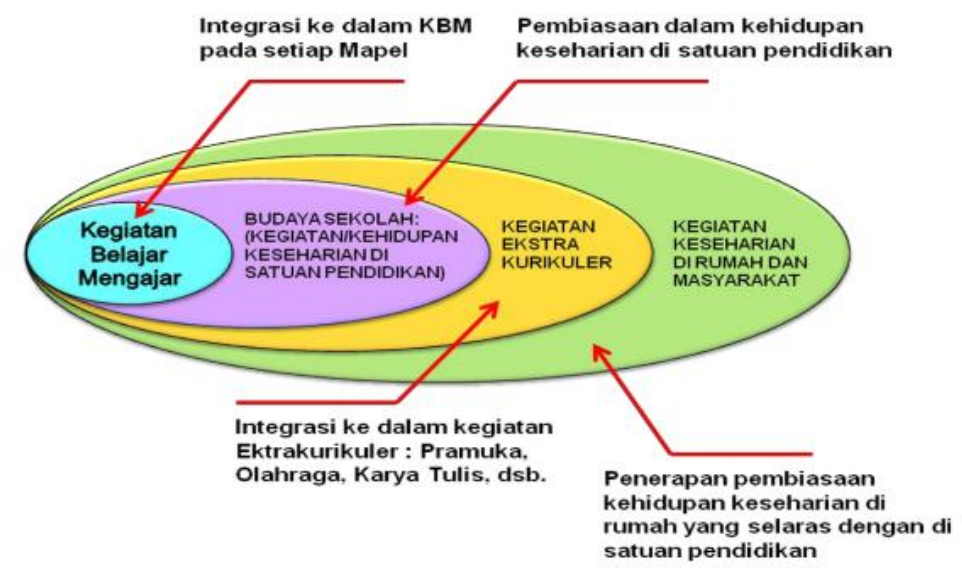

Gambar 1. Pendidikan Karakter di Sekolah (Jalal, 2011)

setiap mata pelajaran menuntut kompetensi yang mengandung nilai-nilai kebaikan dan kehidupan, seperti: kejujuran, keuletan, kerjasama, kompetisi, kebangsaan, sopan santun, kesatuan, sportifitas dan sebagainya. Terdapat beberapa mata pelajaran yang mengandung kompetensi yang lebih sarat dengan sikap dan nilai-nilai dibandingkan dengan mata pelajaran yang lain. Berikut ini adalah beberapa contoh kandungan nilai-nilai dan sikap yang merupakan ujud dari ranah afektif (Jalal, 2011).

Karakter harus tertanam dalam diri seseorang agar menjadi sebuah kebiasaan yang baik. Perlu dipikirkan bersama bagaimana proses pembelajaran yang efektif dalam menanamkan nilai karakter pada anak, karena pada kenyatannya masih banyak pekerjaan rumah yang berkaitan dengan karakter mulai dari tawuran, kemudian perkelahian dan lain sebagainya. Pembelajaran yang disisipkan unsur nilai perlu menjadi isu yang selalu digaungkan dalam proses pembelajaran di kelas. Ini penting agar ketika anak keluar dari sekolah selain dia memiliki kemampuan yang baik juga memiliki karakter yang baik dan mereka bisa membiasakan dirinya menjadi pribadi yang baik pula.

\section{Irisan Pendidikan Karakter dengan Sains}

Pembelajaran sains dapat dijadikan sebagai pendekatan untuk membangun moral, karakter dan akhlak mulia. Melalui pendidikan sains peserta didik akan mengenal dirinya sendiri dan Tuhannya (Zubaidah, 2011)(Prasetyo, 2013)(Mayasari, 2017)(Nofiana \& Julianto, 2018). Hasil penelitian Zuchdi dkk. (2010) menunjukkan bahwa model pendidikan karakter dengan pendekatan komprehensif, yang dipadukan dengan pembelajaran bidang studi dan dilandasi pengembangan kultur sekolah, dapat meningkatkan hasil studi dan kualitas karakter peserta didik. Pendidikan karakter yang diintegrasikan dalam pembelajaran berbagai bidang studi dapat memberikan pengalaman yang bermakna bagi muridmurid karena mereka memahami, menginternalisasi, dan mengaktualisasikan melalui poses pembelajaran. Dengan demikian, nilai-nilai tersebut dapat terserap secara alami lewat kegiatan sehari-hari (Zubaidah, 2011).

Pentingnya sains, bagi pengembangan karakter warga masyarakat dan Negara telah menjadi perhatian para pengembang pendidikan sains di beberapa negara, misalnya Amerika Serikat dan negaranegara anggota Organization for Economic Cooperation and Development (OECD) melalui PISA. Sains diyakini berperan penting dalam pengembangan karakter warga masyarakat dan negara karena kemajuan produk sains yang amat pesat, keampuhan proses sains yang dapat ditransfer pada berbagai bidang lain, dan kekentalan muatan nilai, sikap, dan moral di dalam sains (Zubaidah, 2011). Zuchdi 
Zuchdi dkk. (2010) menjelaskan, sejak tahun 1989, Allan J. MacCormack dan Robert E. Yager mengembangkan lima ranah dalam taksonomi untuk pendidikan sains. Kelima ranah tersebut seperti berikut. Pertama, knowing and understanding (knowledge domain), termasuk: fakta, konsep, hukum (prinsipprinsip), beberapa hipotesis dan teori yang digunakan para saintis, dan masalahmasalah sains dan sosial. Kedua, exploring and discovering (process of science domain), yakni penggunaan beberapa proses sains untuk belajar bagaimana para saintis berpikir dan bekerja. Ketiga, imagining and creating (creativity domain). Terdapat beberapa kemampuan penting manusia dalam domain ini, yaitu mengkombinasikan beberapa objek dan ide melalui cara-cara baru; menghasilkan alternative atau menggunakan objek yang tidak biasa digunakan; mengimajinasikan; memimpikan; dan menghasilkan ide-ide yang luar biasa. Keempat, feeling and valuing (attitudinal domain). Ranah ini mencakup: pengembangan sikap positif terhadap sains secara umum, sains di sekolah, dan para guru sains; pengembangan sikap positip terhadap diri sendiri, misalnya ungkapan yang mencerminkan rasa percaya diri "I can do it!'; pengembangan pengembangan kepekaan, dan penghargaan, terhadap perasaan orang lain; dan pengambilan keputusan tentang masalah-masalah sosial dan lingkungan. Kelima, using and applying (application and connection domain). Beberapa hal yang termasuk ranah penerapan adalah: mengamati contoh konsep- konsep sains dalam kehidupan sehari-hari; menerapkan konsep-konsep dan keterampilan-keterampilan sains yang telah dipelajari untuk masalah-masalah teknologi sehari-hari; mengambil keputusan untuk diri sendiri yang berkaitan dengan kesehatan, gizi, dan gaya hidup berdasarkan pengetahuan sains daripada berdasarkan apa yang "didengar" dan yang "dikatakan" atau emosi; serta memadukan sains dengan subjek-subjek lain (Zubaidah, 2011). Ilustrasi tersebut memberikan gambaran bahwa sains pada dasarnya memberikan pemahaman bahwa manusia merupakan makhluk ciptan Tuhan yang diberikan akal dan piker untuk mampu berkembang dan berpikir secara baik. Seseorang yang memiliki akhlak yang mulia atau memiliki karakter yang baik adalah mereka yang mampu mengenal dengan Tuhannya dan pembelajaran sains memfasilitasi hal tersebut. Pembelajaran sains juga memberikan kebiasaan untuk bersikap objektif dan jujur terhadap hasil yang didapat dari aktivitas sainnya. Ini sifat yang penting dalam membangun karakter yang baik yang harus dibiasakan dalam kehidupan sehari-hari.

\section{KESIMPULAN}

Melalui kajian ini dapat disimpulkan bahwa sains dan karakter memiliki irisan yang keduanya saling berhubungan. Sains memberikan pemahaman tentang manusia dan mengenali penciptanya, aktivitas sains memberikan sifat yang objektif dan jujur dalam menyampaikan hasilnya, dua sikap ini merupakan hal yang penting dalam memberikan pondasi karakter bagi seseorang.

\section{DAFTAR PUSTAKA}

Ani, N. A. (2014). Pendidikan Karakter untuk Siswa SD dalam Perspektif Islam. Mimbar Sekolah Dasar, 1(1), 50-58.

Aqil, D. I. (2017). Literasi Sains Sebagai Konsep Pembelajaran Buku Ajar Biologi Di Sekolah. Wacana Didaktika, 5(02), 160. https://doi.org/10.31102/wacanadidak tika.v5i02.59

Arif, R. M. (2017). Implementasi Pendidikan Karakter dalam Pembelajaran Sains. STILISTIKA: Jurnal Bahasa, Sastra, Dan Pengajarannya, 2(1), 226-239. https://doi.org/10.33654/sti.v2i1.385

Choli, I. (2019). Pembentukan Karakter Melalui Pendidikan Islam. Tahdzib 
Al-Akhlaq: Jurnal Pendidikan Islam, 2(2), $35-52$. https://doi.org/10.34005/tahdzib.v2i2. 511

Hasibuan, A. A., Syah, D., \& Marzuki, M. (2018). Manajemen Pendidikan Karakter Di Sma. Tarbawi: Jurnal Keilmuan Manajemen Pendidikan, 4(02), 191. https://doi.org/10.32678/tarbawi.v4i0 2.1230

Ibrahim, Gunawan, Marwan, \& Jalaluddin. (2019). HAKIKAT PEMBELAJARAN SAING Dalam Inovasi Kurikulum Karakter. SEFA BUMI PERSADA.

Jalal, F. (2011). Akhlak dan Pembangunan Pendidikan Karakter. Milad JSIT.

Kosim, M. (2011). Urgensi pendidikan karakter. Karsa, IXI(1), 85-92.

Kunci, K. (2013). Integrasi Pendidikan Karakter Dalam Perkuliahan. Jurnal Pendidikan Karakter, O(1), 95-107. https://doi.org/10.21831/jpk.v0i1.129 1

Mayasari, T. (2017). Integrasi budaya Indonesia dengan Pendidikan Sains. Prosiding SNPF (Seminar Nasional Pendidikan Fisika), O(0), 12-17. http://e-

journal.unipma.ac.id/index.php/snpf/a rticle/view/1606/1261

Muna, I., Rahayu, S., \& Marfu'ah, S. (2017). Pemahaman Hakikat Sains Dan Inkuiri Ilmiah Calon Guru Kimia. J-PEK (Jurnal Pembelajaran Kimia), 2(2), 15-22. https://doi.org/10.17977/um026v2i22 $017 \mathrm{p} 015$

Nofiana, M., \& Julianto, T. (2018). Upaya Peningkatan Literasi Sains Siswa Melalui Pembelajaran Berbasis Keunggulan Lokal. Biosfer: Jurnal Tadris Biologi, 9(1), 24. https://doi.org/10.24042/biosf.v9i1.28
76

Prasetyo, Z. K. (2013). Pembelajaran Sains Berbasis Kearifan Lokal. PROSIDING: Seminar Nasional Fisika Dan Pendidikan Fisika, 2(1), 246-256.

http://jurnal.fkip.uns.ac.id/index.php/p rosfis1/article/view/3316

Shaumi, A. N. (2015). Pendidikan Kecakapan Hidup (Life Skill) dalam Pembelajaran Sains di SD/MI. Pendidikan Dan Pembelajaran Dasar, 2(2), 246.

Sudrajat, A. (2011). Mengapa Pendidikan Karakter. Jurnal Pendidikan Karakter, I(1), 47-58. https://doi.org/10.21831/jpk.v1i1.131 6

Sugiharto, B. (2011). Konsepsi Guru IPA Biologi SMP Se-Surakarta tentang Hakikat Sains. Seminar Nasional VIII Pendidikan Biologi, 1994, 406-411.

Susanti, R. (2013). Penerapan Pendidikan Karakter Di Kalangan Mahasiswa. AlTa Lim Journal, 20(3), 480-487. https://doi.org/10.15548/jt.v20i3.46

Verawati, N. N. S. P., \& Prayogi, S. (2016). Reviuw Literatur tentang Keterampilan Proses Sains. Prosiding Seminar Nasional Pusat Kajian Pendidikan Sains Dan Matematika, 2(May), 334-336.

Zubaidah, S. (2011). Pembelajaran Sains (IPA) Sebagai Wahana Pendidikan Karakter. Seminar Nasional II "Mewujudkan Pendidik Dan Tenaga Kependidikan Yang Profesional", June, 1-10. 